\title{
Monosomy of chromosome 8 could be considered as a primary preneoplastic event in breast cancer: A preliminary study
}

\author{
FABIOLA A. GARCÍA PARRA-PÉREZ ${ }^{1}$, ANGEL ZAVALA-POMPA ${ }^{1}$, JAVIER PACHECO-CALLEROS ${ }^{1}$, \\ ELVA I. CORTÉS-GUTIÉRREZ ${ }^{2}$, RICARDO M. CERDA-FLORES ${ }^{3}$, \\ SANDRA LARA-MIRANDA ${ }^{1}$ and MARTHA I. DÁVILA-RODRÍGUEZ ${ }^{2}$ \\ ${ }^{1}$ Department of Anatomical Pathology, High Specialty Medical Unit No.25, Mexican Institute of Social Security (IMSS); \\ ${ }^{2}$ Department of Genetics, Biomedical Research Center of Northeast, IMSS; \\ ${ }^{3}$ School of Nursing and Center for Research and Development in Health Sciences, \\ University of Nuevo León, Monterrey, Mexico
}

Received April 14, 2011; Accepted August 23, 2011

DOI: $10.3892 / \mathrm{ol} .2011 .484$

\begin{abstract}
This pilot study analyzed and compared the presence of chromosome 8 aneusomy in Mexican women with breast cancer and adjacent, intraductal, proliferative lesions. To determine the chromosome 8 copy number, we performed fluorescence in situ hybridization in nine patients (1800 cells) who underwent mastectomy. We selected two tissue samples from each patient, one corresponding to the invasive ductal carcinoma (IDC) and the other adjacent to the intraductal proliferative lesion (IPL). Breast tissue from 17 autopsy samples (1700 cells) was used as a control. The number of cells with monosomy, disomy and polysomy per subject and type of tissue were compared among the three groups of tissue with the $\mathrm{RxC}$ statistical software package using 50,000 total replicates. Chromosome 8 aneusomy was found in 66 and $67 \%$ of cells from the IDC and IPL samples, respectively. Monosomy was detected significantly more frequently in IPL compared with IDC samples (49.11 vs. 27.11\%; p=0.0000), whereas polysomy was significantly more frequent in IDC compared with IPL samples (40.11 vs. 16.99\%; p=0.00000). Control cells showed $92.3 \%$ disomy. These findings suggest that polysomy of chromosome 8 is more frequently observed in IDC and that monosomy is more frequent in tissue of IPL. Therefore, monosomy may be considered as a primary preneoplastic event. Future studies should be performed to increase the amount of breast tissue with ductal proliferative changes and with cancer, in order to support the results of this pilot study.
\end{abstract}

Correspondence to: Dr Martha I. Dávila-Rodríguez, División de Genética, Centro de Investigación Biomédica del Noreste, IMSS, 2 de abril No. 501, Colonia Independencia, CP 64720, Monterrey, Nuevo León, México

E-mail: marthadavila@cibinmty.net

Key words: chromosome 8, aneusomy, intraductal proliferative lesions, ductal carcinoma, fluorescence in situ hybridization

\section{Introduction}

Breast cancer constitutes a public health concern and in developing countries this type of cancer continues to be diagnosed at its advanced clinical stages. In Mexico, breast cancer from neoplastic origin is the leading cause of mortality in women aged between 45 and 64 years of age (1). Hyperplasia and atypical hyperplasia of the breast appear to be markers of an increased risk of invasive disease, rather than an obligate precursor, as is the case with intraductal carcinoma (2).

Early events in the carcinogenic continuum of breast cancer are morphologically undetectable and a variety of factors complicate the genetic analysis of early breast neoplasia, including the heterogeneity and lengthy natural history of breast cancer, as well as the difficulty of isolating cells and DNA from microscopic precursor lesions, which may be intimately associated with normal or invasive neoplastic cells (3). Using interphase cytogenetics, chromosome aneuploidy may be detected in archival tissue sections, thus permitting morphologically directed analysis of uncommon or microscopic lesions. Investigations have been conducted on invasive ductal carcinoma (IDC) and its adjacent intraductal proliferative lesions (IPLs), including chromosomal aneusomy (chromosomes 1, 8, 11 and 17 have been found particularly frequently), which is an early event in the development of breast cancer (4-6). Studies focused on chromosome 8 have found that ductal carcinoma shows an increase in the copy number of chromosome 8 in later clinical stages (7-9). Moreover, this abnormality correlates with markers that predict aggressive biological behavior of the tumor (9). Characterization of these alterations in the early stages of breast cancer may have an impact on reducing mortality from breast cancer.

The majority of studies on chromosome imbalances have been conducted on invasive carcinoma and few studies have investigated preinvasive lesions of the breast (10). In the present study, we analyzed and compared the presence of chromosome 8 aneusomy in Mexican women with breast cancer and adjacent IPLs. 
Table I. General characteristics of tissue samples.

\begin{tabular}{lcccc}
\hline & & IPL $^{\mathrm{a}}$ & IDL $^{\mathrm{b}}$ \\
\hline Case no. & Age (years) & $\begin{array}{c}\text { Clinical stage of } \\
\text { tumoral lesion }\end{array}$ & $\begin{array}{c}\text { Traditional classification } \\
\text { (DIN terminology) }\end{array}$ & $\begin{array}{c}\text { Histological }^{\mathrm{c}} \\
\text { grade }^{\mathrm{d}}\end{array}$ \\
\hline 1 & 48 & IIIB & Intraductal carcinoma grade 2 (DIN2) & II \\
2 & 58 & IIB & Usual intraductal hyperplasia & II \\
3 & 63 & IIIA & Usual intraductal hyperplasia & III \\
4 & 59 & IIA & Usual intraductal hyperplasia & II \\
5 & 30 & IIIB & Intraductal carcinoma grade 3 (DIN3) & III \\
6 & 62 & IIIA & Intraductal carcinoma grade 2 (DIN2) & II \\
7 & 30 & IIIB & Usual intraductal hyperplasia & II \\
8 & 58 & IIA & Usual intraductal hyperplasia & II \\
9 & 57 & IIIB & Intraductal carcinoma grade 1 (DIN1) & \\
\hline
\end{tabular}

${ }^{\mathrm{a}}$ Intraductal proliferative lesion, ${ }^{\mathrm{b}}$ Invasive ductal carcinoma, ${ }^{\mathrm{c}} \mathrm{OMS} 2003$, ${ }_{\mathrm{d}}^{\mathrm{S}}$ Carff-Bloom-Richardson system.

\section{Materials and methods}

Sample collection. Study samples were selected from the files of the Surgical Pathology Department at Unidad Médica de Alta Especialidad No. 25, Instituto Mexicano del Seguro Social (IMSS) (Monterrey, Mexico), from mastectomy specimens obtained from patients with a final histopathology diagnosis of IDC (11). Samples were selected from nine patients with ages ranging from 30 to 63 years (mean 51.6). This study was approved by the Ethics Committee of the Unidad Médica. Two formalin-fixed, paraffin-embedded samples of breast tissue blocks were selected for each patient, one block corresponding to IDC and the other to tumor-adjacent breast tissue with the presence of IPLs. For controls, we selected 17 formalin-fixed paraffin-embedded breast tissue blocks from females (mean 22.6 years, range 15-30 years) with a cause of mortality other than breast cancer. Consecutive sections were cut for each sample and applied directly to silanized glass slides. At least one slide from the consecutive sections was stained with hematoxylin and eosin. Sections from each sample were then subjected to histopathological and fluorescence in situ hybridization (FISH) protocols. For all participants included in this study, mastectomy or biopsy was performed by medical indications with the informed consent of the patient or a relative.

Histopathology. Histopathological characteristics of tissue samples are shown in Table I. For IPL tissue, there were four cases of intraductal carcinoma, two cases of florid usualtype hyperplasia and three cases of moderate, usual-type hyperplasia. Atypical hyperplasia was not found in the tissue samples studied. Only one patient in the control group had a family history of breast cancer and no patients in this group had breast disease.

For IDC, all carcinomas included were of the ductal type. IPL samples constituted epithelial ductal hyperplasia of the usual type, atypical hyperplasia and intraductal carcinoma. Usual-type hyperplasia was subdivided into mild, moderate and florid, according to the number of ductal cell lines and architectural patterns (see Table I) (12). Breast tissue samples for the control group were selected according to the patient age and whether they had a normal histological appearance. We considered breast parenchyma normal in the absence of neoplastic processes, either benign or malignant, and we further classified it as active or at rest, depending on the age of the patient and whether the patient was pregnant.

Deparaffinization. Briefly, formalin-fixed, paraffin-embedded, 3-4 $\mu \mathrm{m}$ tissue sections were applied to silanized slides. Slides were then baked at $65^{\circ} \mathrm{C}$ overnight. Specimens were deparaffinized in xylene and fixed in 100\% ethanol for $15 \mathrm{~min}$. Pretreatment with $30 \%$ bisulfide sodium in $2 \mathrm{X}$ saline-sodium citrate (SSC) buffer ( $\mathrm{pH} 7.0$ ) for $15 \mathrm{~min}$ at $45^{\circ} \mathrm{C}$ was followed by 1 min washes in $2 \mathrm{X} \mathrm{SSC} \mathrm{(pH} \mathrm{7.0).} \mathrm{Treatment} \mathrm{with} \mathrm{proteinase} \mathrm{K}$ ( $400 \mathrm{ml}$ stock solution, $25 \mathrm{mg} / \mathrm{ml}$ ) in $40 \mathrm{ml} 2 \mathrm{X} \mathrm{SSC}$ (pH 7.0) for $15 \mathrm{~min}$ at $45^{\circ} \mathrm{C}$ was followed by dehydration for $2 \mathrm{~min}$, each in an increasing series of ethanol (70,80 and 100\%).

Hybridization. Tissues were hybridized with probes specific for repetitive alphoid sequences at the centromeric region of chromosome 8 (CEP8 SpectrumOrange; Vysis Inc., Downers Grove, IL, USA), and contrasted using 4',6-diamidino-2-phenylindole (DAPI) according to the manufacturer's instructions. Slides were examined using a fluorescent microscope (Axiophot; Carl Zeiss, Jena, Germany) equipped with an appropriate filter combination for DAPI/fluorescein isothiocyanate (FITC)/ Texas Red (430 ex/468 em and 532 ex) and a x100 objective. FISH images were captured using a Color Video Camera (3CCD; Sony, Tokyo, Japan).

Signal scoring. Scoring was performed independently by cytogenetic technicians who had no clinical information or knowledge of other histological and pathological results at the time of scoring. The categories for the number of signals per nucleus were 1,2 and $\geq 3$, indicating monosomy, disomy and polysomy, respectively. In each tissue, the number of clear, distinct signals in 100 non-overlapping nuclei were counted. Evaluation of the slides was carried out according to accepted criteria (8). FISH signals were expressed as the mean number 
Table II. Distribution of the frequency of chromosome 8 signals in ductal cells in the IDC, IPL and control tissue samples.

\begin{tabular}{lccc}
\hline & $\begin{array}{l}\text { Control } \\
\mathrm{n}(\%)\end{array}$ & $\begin{array}{l}\mathrm{IPL}^{\mathrm{a}} \\
\mathrm{n}(\%)\end{array}$ & $\begin{array}{l}\mathrm{IDC}^{\mathrm{b}} \\
\mathrm{n}(\%)\end{array}$ \\
\hline Cases & 17 & 9 & 9 \\
Cells & 1700 & 900 & 900 \\
Disomy & $1569(92.30)$ & $305(33.89)$ & $295(32.78)$ \\
Aneusomy & $131(7.70)$ & $595(66.11)$ & $605(67.22)$ \\
Monosomy & $108(6.35)$ & $442(49.11)$ & $244(27.11)$ \\
Polysomy & $23(1.35)$ & $153(16.99)$ & $361(40.11)$ \\
\hline
\end{tabular}

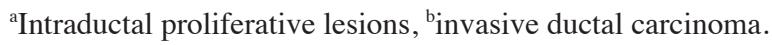

of signals for the percentage of cells counted. Aneusomy was regarded as the sum of cells with monosomy and polysomy. The evaluation of slides was conducted by two observers and the results had an interobserver $\kappa$ value of 0.97 .

Statistical analysis. The number of cells with monosomy, disomy and polysomy per subject and type of tissue were compared among the three groups of tissue (IDC, IPL and control) with the $\mathrm{RxC}$ statistical software package of Miller, using 50,000 total replicates (13).

\section{Results}

The frequency of aneusomy of chromosome 8 between groups is shown in Table II. The percentage of disomic cells was significantly greater in the control samples $(92.3 \%)$ compared with the other tissue samples (IDC, 32.78\% and IPL, 33.89\%; $\mathrm{p}=0.000000)$. For aneusomy, we observed the opposite phenomenon. In other words, the percentage of aneusomy was significantly lower in the control tissue $(7.7 \%)$ compared with other tissues (IDC, 67.22\% and IPL, 66.11\%; p=0.000000). A comparison of IDC and IPL tissue samples showed that monosomy was significantly more frequent in IPL tissue (49.11 vs. $27.11 \%$; $\mathrm{p}=0.00000)$ whereas polysomy was significantly more frequent in IDC tissue (40.11 vs. $16.99 \%$; $\mathrm{p}=0.00000$ ). Representative images of IPL and IDC entities of case 7 are shown in Fig. 1.

\section{Discussion}

Normal and cancerous cell populations continuously evolve, posing a major challenge for effective cancer treatment (14). The development and progression of breast cancer is driven by the accumulation of genetic alterations, including nonrandom chromosome aneusomy in all or part of the tumor cell population (15). This accumulation of genetic alterations is an early event that is morphologically undetectable (3). Unlike studies on DNA analysis that applied to the overall results (16-18), chromosome aneuploidy may be detected using interphase cytogenetics, allowing the morphologically directed analysis of uncommon or microscopic lesions and providing the potential to explore biomarkers. Breast cancer has three tumor markers currently in clinical use for selecting patients and monitoring therapy, which are necessary for diagnosis or prognosis (19).

Our findings show that aneusomy of chromosome 8 is a more frequent polysomy in IDC tissue, as previously reported $(6,9,10,20)$. With respect to IPL, our results showed that monosomy occurred more frequently in this tissue. Similar results have been found in three studies using the same methodology.
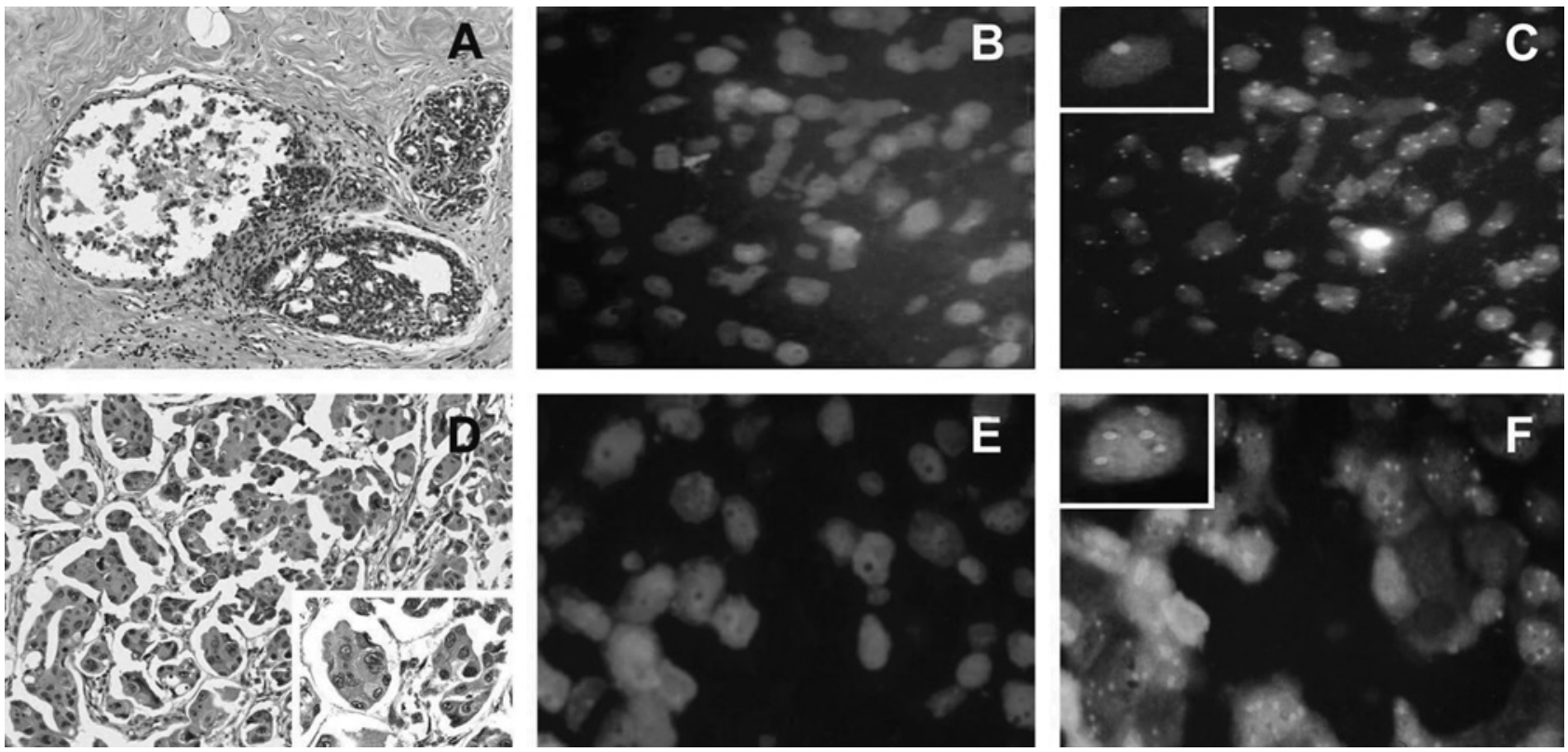

Figure 1. (A) Preneoplastic lesion (usual intraductal hyperplasia). (H\&E; LM, x10). (B) Hyperplasia with DAPI (4'6-diamidino-2-phenylindole), (FM, x40). (C) Fluorescence in situ hybridization, probe CEP8 SpectrumOrange, Vysis (FM, x63); bottom left, magnification of one signal (monosomy). (D) Ductal carcinoma (H\&E; ML, x10; x40 bottom right). (E) Neoplastic cells with DAPI (MF, x63). (F) Fluorescence in situ hybridization, probe CEP8 SpectrumOrange, Vysis (FM, x63), bottom left, magnification of five signal (polysomy). 
An analysis of aneuploidy in certain chromosomes $(1,7,16$, 17 and $\mathrm{X}$ ), including chromosome 8 , in tissue sections of preinvasive breast cancer lesions (lobular carcinomas in situ, ductal carcinomas in situ and proliferative lesions) from 16 patients found that none of the proliferative lesions exhibited chromosome gains. However, monosomy was evidenced, which was more clear in lobular carcinoma in situ (6/9 patients), suggesting that there are distinct pathological subsets of preinvasive, neoplastic breast cancer that have divergent patterns of genetic instability (3). Analysis of aneuploidy for chromosome 8 (including chromosomes 7, 16 and 17) between foci of 12 ductal carcinoma in situ and a representative area of coexisting invasive neoplasm showed that cells with monosomy occur more frequently in preinvasive cancer for all of the chromosomes (10 vs. 16\%, p=0.01) (6). An analysis of aneuploidy in 28 cases of ductal carcinoma in situ for six chromosomes $(1,8,7,16,17$ and $\mathrm{X})$ showed the presence of monosomy in grade I (29\%) and II (26\%) lesions, in contrast to grade III (4\%) with $88 \%$ trisomy/polysomy (21). Unlike previous studies, the focus of this study was only on breast tissue with ductal proliferative changes and the classification of these changes, which may have allowed for clear observation of the aneusomy of chromosome 8 .

Few studies have investigated preinvasive lesions. There is a theory that the transition of stable diploid to unstable aneuploidy cell species is the primary cause of preneoplastic and neoplastic genomic instability, and of cancer (22). However, this biologically crucial event may be caused by extremely limited genomic changes as the value of the DNA index performed by flow cytometry may not be essential on its own (16).

Chromosome 8 may be of particular importance in breast cancer as patients with this disease frequently exhibit numerous chromosomal abnormalities, and cytogenetic data studies suggest that abnormalities occur early in tumorigenesis $(6,8,23$ ). Aberrations in chromosome 8 (gain 8q24.3, $8 \mathrm{q} 24.22,8 \mathrm{q} 24.21,8 \mathrm{q} 22.1,8 \mathrm{q} 22.2,8 \mathrm{q} 22.3$ and/or deletion $8 \mathrm{p} 23.3,8 \mathrm{p} 23.2,8 \mathrm{p} 23.1,8 \mathrm{p} 21.3,8 \mathrm{p} 21.2)$ may contribute to resistance to neoadjuvant chemotherapy in ductal-type breast cancer (24). Aneuploidy plays an active role in carcinogenesis; however, its role remains controversial (25).

Notably, molecular studies on chromosome 8 provide a link to interphase cytogenetic abnormalities. Chromosome 8 harbors genes considered to be involved in breast tumor development and progression, such as the N-myc downstreamregulated gene-1, Ndrg-1. One of the well-documented links between $N d r g-1$ and pathophysiology is its association with the inhibition of tumor metastasis. The expression of $\mathrm{Ndrg}-\mathrm{I}$ mRNA is downregulated in tumor cells and individuals with higher levels of Ndrg-1 mRNA have greater survival rates (26). Recent genome-wide association studies have found multiple genetic variants on chromosome $8 \mathrm{q} 24$ that are significantly associated with an increased susceptibility to breast cancer. It has been suggested that these $8 \mathrm{q} 24$ genetic variant(s) affect Myc expression by altering its regulation or amplification status. Multiple enhancer elements are present within this region, which regulate the transcription of Myc (27).

In conclusion, these findings suggest that polysomy of chromosome 8 is more frequent in IDC and that monosomy is more frequent in the tissue of IPL, therefore, monosomy may be considered as a primary preneoplastic event. Future studies should be performed on greater numbers of breast tissue with ductal proliferative changes and with cancer, in order to support the results of this pilot study.

\section{Acknowledgements}

We would like to acknowledge the Asociación Mexicana de Asistencia a Niños con Enfermedades Catastróficas (AMANEC) for their technical support in the capture of hematoxylin and eosin micro-images. We are grateful to Sanjuana Leticia Guardado Limon, Rene Reynaga Piña and Hugo Alejandro Gonzalez Hernandez for their excellent technical assistance.

\section{References}

1. Cardenas Sanchez J and Sandoval Guerrero F: Tercera Revisión del Consenso Nacional Sobre el Diagnóstico y Tratamiento del Cáncer Mamario. Ginecol Obstet Mex 78: 199-212, 2010.

2. Cummings MC, Aubele M, Aubele M, et al: Increasing chromosome 1 copy Lumber parallels histological progression in breast carcinogenesis. Br J Cancer 82: 1204-1210, 2000.

3. Visscher DW, Wallis TL and Crissman JD: Evaluation of chromosome aneuploidy in tissue sections of preinvasive breast carcinomas using interphase cytogenetics. Cancer 77: 315-320, 1996.

4. Rojas-Atencio A, González L, Urdaneta K, et al: Cytogenetic findings in ductal carcinoma of the breast. Invest Clin 40: 179-189, 1999.

5. Bieche I and Lidereau R: Genetic alterations in breast cancer. Genes Chromosomes Cancer 14: 227-251, 1995.

6. Mendelin J, Grayson M, Wallis T, et al: Analysis of chromosome aneuploidy in breast carcinoma progression by using fluorescence in situ hybridization. Lab Invest 79: 387-393, 1999.

7. Mark HF, Taylor W, Afify A, et al: Stage I and stage II infiltrating ductal carcinoma of the breast analyzed for chromosome 8 copy number using fluorescent in situ hybridization. Pathobiology 65: 184-189, 1997.

8. Mark HF, Taylor W, Brown S, et al: Abnormal chromosome 8 copy number in stage I to stage IV breast cancer studied by fluorescence in situ hybridization. Cancer Genet Cytogenet 108: 1-5, 1999.

9. Afify A, Bland KI and Mark HFL: Fluorescent in situ hybridization assessment of chromosome 8 copy number in breast cancer. Breast Cancer Res Treat 38: 201-208, 1996.

10. Krishnamurthy S, Zhao L, Hayes K, et al: Feasibility and utility of using chromosomal aneusomy to further define the cytologic categories in nipple aspirate fluid specimens. Cancer, 102: 322-327, 2004.

11. Tavassoli FA and Devilee P: World Health Organization classification of tumors. Pathology and genetics of tumors of the breast and female genital organs. Lyon, France, IARC Press, 2003.

12. Rosen Paul Peter: Breast Pathology, Diagnosis by Needle Core Biopsy. 2nd edition. Lippincontt Williams/Wilkins, Baltimore, MD, USA, pp84-123, 2006.

13. Guo SW and Thompson EA: Technical Report No. 187. Departmental of Statistics, University of Washington, 1989.

14. Park SY, Gönen M, Kim HJ, et al: Cellular and genetic diversity in the progression of in situ human breast carcinomas to an invasive phenotype. J Clin Invest 120: 401-403, 2010.

15. Botti C, Pescatore B, Mottolese M, et al: Incidence of chromosomes 1 and 17 aneusomy in breast cancer and adjacent tissue: an interphase cytogenetic study. J Am Coll Surg 190: 530-539, 2000.

16. Ottesen GL, Christensen IJ, Larsen JK, et al: DNA aneuploidy in early breast cancer. Br J Cancer 72: 832-839,1995.

17. Aubele M, Cummings M, Walsch A, et al: Heterogeneous chromosomal aberrations in intraductal breast lesions adjacent to invasive carcinoma. Anal Cell Pathol 20: 17-24, 2000.

18. Xu S, Wei B, Zhang H, et al: Evidence of chromosomal alterations in pure usual ductal hyperplasia as a breast carcinoma precursor. Oncol Rep 19: 1469-1475, 2008.

19. Kulasingam V and Diamandis E: Strategies for discovering novel cancer biomarkers through utilization of emerging technologies. Nat Clin Pract Oncol 5: 588-599, 2008. 
20. Roka S, Fiegl M, Zojer N, et al: Aneuploidy of chromosome 8 as detected by interphase fluorescence in situ hybridization is a recurrent finding in primary and metastatic breast cancer. Breast Cancer Res Treat 48: 125-133, 1998.

21. Visscher D, Jimenez RE, Grayson M, et al: Histopathologic analysis of chromosome aneuploidy in ductal carcinoma in situ. Hum Pathol 31: 201-207, 2000.

22. Duesberg P, Fabarius A and Hehlmann R: Aneuploidy, the primary cause of the multilateral genomic instability of neoplastic and preneoplastic cells. IUBMB Life 56: 65-81, 2004.

23. Deng G, Lu Y, Zlotnikov G, et al: Loss of heterozygosity in normal tissue adjacent to breast carcinomas. Science 274: 2057-2059, 1996.
24. Han S, Park K, Shin E, et al: Genomic change of chromosome 8 predicts the response to taxane-based neoadjuvant chemotherapy in node-positive breast cancer. Oncol Rep 24: 121-128, 2010.

25. Dey P: Aneuploidy and malignancy: an unsolved equation. J Clin Pathol 57: 1245-1249, 2004.

26. Kovacevic Z and Richardson DR: The metastasis suppressor, Ndrg-1: a new ally in the fight against cancer. Carcinogenesis 27: 2355-2366, 2006.

27. Sotelo J, Esposito D, Duhagon M A, et al: Long-range enhancers on 8q24 regulate c-Myc. Proc Natl Acad Sci USA 107: 3001-3005, 2010. 